\title{
Associations of the lactase persistence allele and lactose intake with body composition among multiethnic children
}

\author{
Adil J. Malek • Yann C. Klimentidis • \\ Kenneth P. Kell · José R. Fernández
}

Received: 17 October 2012/ Accepted: 18 February 2013/Published online: 12 March 2013

(c) Springer-Verlag Berlin Heidelberg 2013

\begin{abstract}
Childhood obesity is a worldwide health concern with a multifaceted and sometimes confounding etiology. Dairy products have been implicated as both proand anti-obesogenic, perhaps due to the confounding relationship between dairy, lactose consumption, and potential genetic predisposition. We aimed to understand how lactase persistence influenced obesity-related traits by observing the relationships among lactose consumption, a single nucleotide polymorphism (SNP) near the lactase $(L C T)$ gene and body composition parameters in a sample of multiethnic children ( $n=296,7-12$ years old). We hypothesized that individuals with the lactase persistence (LP) allele of the LCT SNP (rs4988235) would exhibit a greater degree of adiposity and that this relationship would be mediated by lactose consumption. Body composition variables were measured using dual X-ray absorptiometry and a registered dietitian assessed dietary intake of lactose. Statistical models were adjusted for sex, age, pubertal stage, ethnic group, genetic admixture, socio-economic status, and total energy intake. Our findings indicate a positive, significant association between the LP allele and body mass index $(p=0.034)$, fat mass index (FMI) $(p=0.043)$, and waist circumference $(p=0.008)$, with associations being stronger in males than in females. Our
\end{abstract}

\footnotetext{
A. J. Malek · K. P. Kell · J. R. Fernández $(\bowtie)$ Department of Nutrition Sciences, University of Alabama at Birmingham, Webb 449A-1720 Second Avenue South, Birmingham, AL 35294-3360, USA

e-mail: jose@uab.edu

Y. C. Klimentidis

Division of Epidemiology and Biostatistics, Mel and Enid Zuckerman College of Public Health, University of Arizona, Tucson, AZ 85724, USA
}

results also reveal that lactose consumption is positively and nearly significantly associated with FMI.

Keywords Lactose - Obesity · Children - Genetics · Lactase persistence $\cdot$ Body composition

\section{Introduction}

Childhood obesity and associated cardiometabolic disease risk continue to rise at an alarming rate in the United States (Ogden et al. 2006). Much of the excess weight gain in obese individuals is comprised of adipose tissue, resulting from various factors, including the abundant accessibility of calorie-dense, nutrient-poor foods (Bouchard 1991). While an overall chronic positive energy imbalance contributes to increased adiposity, evidence suggests that specific micro and/or macronutrients in the diet can also play significant roles in altering body composition (Swinburn et al. 2006; Hanks et al. 2010). For example, our laboratory has recently shown a positive indirect relationship between calcium and total body fat in children, mediated via resting energy expenditure (Hanks et al. 2010). While other populations may chiefly derive calcium from other sources (Murakami et al. 2006), dairy is the primary source of calcium in the United States diet. Dairy is also a main source of the disaccharide lactose, that is, "milk sugar"(I.O.M. 2010), although secondary sources of lactose exist (Matthews et al. 2005). The lactase enzyme is essential for the metabolism of lactose (Buzinaro et al. 2006), and the persistence of this enzyme throughout adulthood is strongly genetically controlled.

Lactase production typically diminishes overtime, eventually resulting in an inability to digest and utilize lactose, known as lactose intolerance (LI). In mammals, 
including most humans (Swallow et al. 2001), LI is experienced sometime after weaning due to tight regulation of $L C T$ throughout development. This regulation allows for nominal lactase expression during the fetal stage, abundant expression at birth, and a progressive decrease in expression overtime in a majority of individuals. However, among certain populations, the ability to digest lactose persists across the lifespan (Büller et al. 1990; Lacey et al. 1994; Sebastio et al. 1989).

Lactase persistence, in some individuals, is highly associated with a particular single nucleotide polymorphism (SNP) located 13,910 base pairs upstream from the site of lactase transcription (Swallow et al. 2001). This SNP is variable for either cytosine (C) or thymine (T) and is located within intron 13 of the MCM6 gene on chromosome 2 (Wang et al. 1995, 1998). The "C" variant functions as a cis-element down-regulator by coding for a binding motif that affects an AP2 site on the lactase gene promoter causing delayed transcription and decreased lactase production. The " $\mathrm{T}$ " variant disrupts this binding motif and allows lactase production to occur at a rapid pace. Thus, the presence of a " $T$ " variant is associated with unhindered gene transcription and lactase production, whereas a homozygous genotype for the " $\mathrm{C}$ " variant is associated with dysfunctional lactase production which results in lactose intolerance (Enattah et al. 2002; Olds and Sibley 2003).

The distribution of this allele is varied across human populations. The frequency of the lactase persistence (LP) allele is most common in people of European ancestry as well as some African, Middle Eastern, and Southern Asian groups; however, it is nearly absent in the rest of the world (Itan et al. 2010). There is strong evidence that the selective pressures that led to the LP allele being common in these geographic regions originated from the dairying practices begun by early European and West Asian farmers $<10,000$ years ago (Bersaglieri et al. 2004; Scrimshaw and Murray 1988). This and other lactase persistence alleles found in African and other populations (Imtiaz et al. 2007; Ingram et al. 2007; Tishkoff et al. 2007) likely conferred a selective advantage by providing an additional source of energy and preventing the malabsorption of dairy nutrients associated with lactose (Debongnie et al. 1979).

While the LP allele may have been beneficial in the context of limited caloric resources, in modern American society, individuals with the lactase persistence allele may experience adverse health consequences since the production of lactase allows for more efficient nutrient absorption from dairy and other ingested foods and, thereby, lead to an increased BMI. Previous studies have confirmed a positive association between the LP allele and BMI (Kettunen et al. 2010; Corella et al. 2011; Almon et al. 2012); however, in children, association studies have shown increased dairy consumption in carriers of the LP allele but no marked association with BMI levels (Almon et al. 2010). Additionally, others have described a negative association between dairy intake, regardless of fat content, and BMI (Slyper and Huang 2009), further implicating dairy products as both pro and anti-obesogenic (Remesar et al. 1999; Berkey et al. 2005; Skinner et al. 2003; Lehtimäki et al. 2006). In an attempt to further understand the complex relationships among lactose intake (rather than dairy alone), genetic variation and body composition, we evaluated if individuals with the lactase persistence (LP) allele of the LCT SNP (rs4988235) would exhibit a greater degree of adiposity, potentially mediated by lactose consumption.

\section{Methods and procedures}

\section{Study participants}

The sample included 296 participants ranging from 7-12 years of age, classified by parents as AfricanAmerican (AA; $n=100$ ), European-American (EA; $n=116$ ), or Hispanic-American (HA; $n=80$ ). The study was a cross-sectional study evaluating population differences in health-related outcomes, and participants were randomly recruited through flyers, local media advertisement, public health fairs, and word of mouth from the greater Birmingham, AL metropolitan area. Given the health disparity focus of the study, and based on the US Census 2000 estimates of $1.8 \%$ HA, $36 \%$ AA and $60 \%$ EA, Hispanic-Americans were overrepresented, and European-Americans were underrepresented in this sample (U.S.C.B. 2000). Physician examination determined that all participants had no medical diagnoses that would affect body composition, and that all participants were pubertal stage $\leq 3$ (Marshall and Tanner 1968). Data collection was conducted between 2004 and 2008 at the University of Alabama at Birmingham (UAB) General Clinical Research Center and Department of Nutrition Sciences. Informed assent and consent were obtained from children and parents in accordance with the ethical standards of the responsible committee on human experimentation, as approved and regulated by the UAB Institutional Review Board.

\section{Body composition}

Body weight was measured to the nearest $0.1 \mathrm{~kg}$ in light clothing and without shoes (Scale-tronix $6702 \mathrm{~W}$; Scaletronix Carol Stream, IL). Height was determined with a mechanical stadiometer. Both of these values were used to calculate body mass index (BMI) [weight $(\mathrm{kg}) / \mathrm{height}$ $\left(\mathrm{m}^{2}\right)$ ]. Waist circumference was measured just above the hipbone using a flexible tape with a tension regulating 
device. Total fat mass, total lean mass, total bone mineral content, trunk fat mass, leg fat mass, percent trunk fat mass, percent leg fat mass, and percent total fat mass were determined by dual-energy X-ray absorptiometry (DXA) (Lunar Radiation Corp., Madison, WI). DXA scans were taken with subjects in light clothing while lying on their backs with arms at their sides. Pediatric software (encore 2002 version 6.10.029) was used to analyze the scans. Values were used to calculate fat mass index (FMI) [fat mass $(\mathrm{kg}) /$ height $\left(\mathrm{m}^{2}\right)$ ], lean mass index (LMI) [lean mass $(\mathrm{kg}) /$ height $\left(\mathrm{m}^{2}\right)$ ], and bone mass index (BMCi) [total bone mineral content $(\mathrm{kg}) /$ height $\left.\left(\mathrm{m}^{2}\right)\right]$.

\section{Socioeconomic status}

Because socioeconomic status (SES) plays a role as an environmental factor influencing dietary intake and adiposity, the Hollingshead 4-factor index of social class (Cirino et al. 2002) was used to determine SES. The SES score was calculated from a combination of educational attainment and occupational prestige for all working parents in the child's family. Scores range from 8 to 66 , with higher scores indicating higher SES.

\section{Dietary recall}

A registered dietitian conducted two 24-h dietary recalls on subjects. Portion sizes were determined by providing cup and bowl size estimates, and each recall was performed in the presence of at least one parent. A registered dietitian entered dietary data into the Nutrition Data System for Research version 2006 (Nutrition Coordinating Center, University of Minnesota, Minneapolis, Minnesota), and the values from both visits were averaged for analysis. Three dietary variables were considered in the study: (a) total daily energy intake expressed in total $\mathrm{kcal} / \mathrm{day}$, (b) total daily lactose intake expressed in $\mathrm{g} / \mathrm{day}$, and (c) percent calories from lactose, defined as (lactose $\mathrm{kcal} /$ total $\mathrm{kcal}) \times 100$. Although dairy intake was collected as five categories (yogurt, low fat milk, full fat milk, cheese, "other dairy") based on the number of servings of each item, dairy variables were not utilized in this study since one serving of dairy was not equivalent in lactose, calories, or quantity to another form of dairy serving (data not shown). Therefore, combining servings across dairy categories in order to appreciate total dairy intake would not result in consistent measures of lactose, calories, or quantity.

Genotyping and Hardy-Weinberg equilibrium

A blood draw was used to obtain DNA from all participants. Genotypes for the LCT SNP (rs4988235—C/T) were determined by the Illumina Golden Gate assay at the UAB Heflin Genotyping Core. The SNP was tested for HardyWeinberg equilibrium in the entire sample, and within each ethnic group using SAS (SAS version 9.2 software; SAS Institute, Cary, NC).

\section{Genetic admixture analysis}

Genetic admixture was determined by genotyping Ancestry Informative Markers (AIMs), performed at Prevention Genetics (Marshfield, WI) using the Chemicon Amplifluor SNPs Genotyping System coupled with Array/Tape technology as previously described (Casazza et al. 2009). A panel of 142 AIMs (Klimentidis et al. 2011) was used to estimate the genetic admixture proportions of each subject. The information provided by these markers reveals each subject's estimated admixture percentage for geographically separated West African, Amerindian, and European parental populations by using the maximum likelihood algorithm described by (Parra et al. 1998).

\section{Statistical analysis}

The frequency of the " $\mathrm{T}$ " variant (LP allele) for the $L C T$ SNP was determined in the total sample and within each ethnic group. The allele was then tested for association with body composition and anthropometric measures using the dominant genetic model as opposed to the additive model due to the sufficient biological activity of lactase with only one copy of the "T" allele (Kettunen et al. 2010). Thus, C/T and T/T genotypes were represented as LP, and $\mathrm{C} / \mathrm{C}$ was represented as non-LP in the data set. After failing tests for normality, the following variables were either logtransformed or inverse-transformed: BMI, FMI, BMCi, percent total fat, leg adiposity, percent leg fat, trunk adiposity, percent trunk fat, and waist circumference. Linear regression analysis was used to evaluate the association between the LCT SNP and body composition and anthropometric measures, after adjusting for the following covariates: Tanner stage, sex, age, ethnic group, total daily energy intake, genetic admixture, and socioeconomic status. The SNP was tested in the entire sample first and then tested within each ethnic group and sex to determine if any significant differences existed among groups. Additional correlation and t-tests were run to compare measures of lactose consumption among population sub-groups in our sample.

The association of the SNP with BMI was tested first. Then, each body mass component was tested individually in order to determine if any particular component was driving the association with BMI. Additionally, FMI, LMI, and $\mathrm{BMCi}$ were used to better understand the body mass partitioning. The remaining body composition and 
anthropometric variables were used to further explore the relationship between said variables and the LCT SNP.

\section{Results}

Allele frequency and Hardy-Weinberg equilibrium

The frequency of individuals with at least one LP allele (along with sample characteristics) was tabulated in the entire sample and within ethnic groups, as shown in Table 1.

The LCT SNP was tested for Hardy-Weinberg equilibrium (HWE) in the entire sample and within each ethnic group. In the entire sample, the LCT SNP was not in Hardy-Weinberg equilibrium $(p<0.0001)$; however, the LCT SNP was in Hardy-Weinberg equilibrium within each of the ethnic groups (EA: $p=0.277$; AA: $p=0.823$; HA: $p=0.1055)$.

\section{Association of body composition with LP allele}

Our analysis started with exploring the relationship between the LP allele and BMI in the context of the previously described model (Table 2). A significant ( $p=0.034)$, positive association between the LP allele and BMI was found in the entire sample (Table 2). This association was significant among males $(p=0.045)$, but not females ( $p=0.372$ ) (Table 3$)$. Although the associations between the LP allele and BMI were positive in all three ethnic groups, none were statistically significant (Table 4).

Table 1 Sample characteristics by LP status (mean \pm SD)

\begin{tabular}{lll}
\hline & Non-LP $(n=144)$ & LP $(n=152)$ \\
\hline $\begin{array}{l}\text { Total daily lactose intake } \\
\text { (g/day) }\end{array}$ & $15.97 \pm 9.79$ & $19.32 \pm 11.41$ \\
$\begin{array}{l}\text { Total daily energy intake } \\
\quad(\mathrm{kcal} / \text { day) }\end{array}$ & $1,843.93 \pm 460.01$ & $1,924.40 \pm 462.68$ \\
Height $(\mathrm{cm})$ & $138.57 \pm 10.20$ & $140.00 \pm 10.80$ \\
Weight $(\mathrm{kg})$ & $36.22 \pm 9.54$ & $36.75 \pm 9.46$ \\
BMI $\left(\mathrm{kg} / \mathrm{m}^{2}\right)$ & $18.62 \pm 3.00$ & $18.53 \pm 3.02$ \\
FMI & $4.46 \pm 0.25$ & $4.52 \pm 2.30$ \\
Tanner I (\%) & 30.4 & 34.1 \\
Tanner II (\%) & 10.1 & 12.8 \\
Tanner III (\%) & 8.1 & 4.4 \\
Male (\%) & 27.7 & 26.4 \\
Female (\%) & 20.9 & 25.0 \\
European-American (\%) & 6.1 & 33.1 \\
African-American $(\%)$ & 25.0 & 8.8 \\
Hispanic-American (\%) & 17.6 & 9.5 \\
\hline
\end{tabular}

${ }^{a}$ Percentages are given as the percentage of the total population
Table 2 Association of phenotypes and the LP allele in total population

\begin{tabular}{lll}
\hline Phenotype & $p$ value & $\beta$ coefficient \\
\hline Body mass index (BMI) & $0.0335^{*}$ & 0.0246 \\
Fat mass index (FMI) & $0.0428^{*}$ & 0.4864 \\
Bone mass index (BMCi) & 0.3453 & 0.0167 \\
Lean mass index (LMI) & 0.5884 & 0.0096 \\
Percent total fat & $0.0169^{*}$ & 0.1415 \\
Leg adiposity & $0.0324^{*}$ & 0.1432 \\
Percent leg fat & $0.0176^{*}$ & 0.1196 \\
Trunk adiposity & 0.0944 & 0.1511 \\
Percent trunk fat & $0.0440^{*}$ & 0.1436 \\
Waist circumference & $0.0077^{*}$ & 0.0006 \\
\hline
\end{tabular}

$* p$ value $<0.05$

a All models adjusted for the following covariates: tanner stage, sex, age, ethnic group, total daily energy intake, genetic admixture, and socioeconomic status

Table 3 Association of phenotypes and LP allele by gender

\begin{tabular}{|c|c|c|c|c|}
\hline \multirow[t]{2}{*}{ Phenotype } & \multicolumn{2}{|l|}{ Male } & \multicolumn{2}{|l|}{ Female } \\
\hline & $p$ value & $\begin{array}{l}\beta \\
\text { coefficient }\end{array}$ & $p$ value & $\begin{array}{l}\beta \\
\text { coefficient }\end{array}$ \\
\hline $\begin{array}{l}\text { Body mass index } \\
\text { (BMI) }\end{array}$ & $0.0454 *$ & 0.0033 & 0.3722 & 0.0015 \\
\hline Fat mass index (FMI) & $0.0122 *$ & 1.0329 & 0.8151 & -0.0548 \\
\hline $\begin{array}{l}\text { Bone mass index } \\
\text { (BMCi) }\end{array}$ & 0.8022 & 0.0063 & 0.4533 & 0.0192 \\
\hline Lean mass index & 0.6027 & 0.0113 & 0.8422 & 0.0058 \\
\hline Percent total fat & $0.0157 *$ & 0.2248 & 0.8967 & 0.0094 \\
\hline Leg adiposity & $0.0333 *$ & 0.2278 & 0.9727 & 0.0028 \\
\hline Percent leg fat & $0.0258 *$ & 0.1838 & 0.7985 & 0.0145 \\
\hline Trunk adiposity & $0.0457 *$ & 0.2700 & 0.8872 & -0.0167 \\
\hline Percent trunk fat & $0.0165 *$ & 0.2628 & 0.7357 & -0.0306 \\
\hline Waist circumference & $0.0450 *$ & 0.0008 & 0.2688 & 0.0004 \\
\hline
\end{tabular}

Next, our analyses sought to elucidate the association of the allele with bone (BMCi), adipose (FMI), and lean tissues (LMI). In the overall sample, FMI was the only component that demonstrated a positive, significant association with the LP allele $(p=0.043)$, with neither LMI $(p=0.588)$ nor BMCi $(p=0.345)$ displaying significant relationships (Table 2). In EAs (Table 4), FMI trended toward significance $(p=0.081)$, and LMI was positively associated $(p=0.024)$ with the LP allele. In AAs and HAs, none of the tissue compartments showed a significant or near-significant relationship with the LP allele. In males, 
Table 4 Association of phenotypes and LP allele by ethnicity

\begin{tabular}{|c|c|c|c|c|c|c|}
\hline \multirow[t]{2}{*}{ Phenotype } & \multicolumn{2}{|c|}{ European-Americans } & \multicolumn{2}{|c|}{ African-Americans } & \multicolumn{2}{|c|}{ Hispanic-Americans } \\
\hline & $p$ value & $\beta$ coefficient & $p$ value & $\beta$ coefficient & $p$ value & $\beta$ coefficient \\
\hline Body mass index (BMI) & 0.1260 & 0.0036 & 0.2348 & 0.0024 & 0.2434 & 0.0022 \\
\hline Fat mass index (FMI) & 0.0808 & 0.8670 & 0.4145 & 0.3860 & 0.1372 & 0.3963 \\
\hline Bone mass index (BMCi) & 0.9371 & -0.0026 & 0.1776 & 0.0452 & 0.7302 & 0.0105 \\
\hline Lean mass index & $0.0235^{*}$ & 0.0775 & 0.7637 & -0.0098 & 0.7837 & -0.0078 \\
\hline Percent total fat & 0.3868 & 0.1087 & 0.2397 & 0.1222 & 0.0787 & 0.1472 \\
\hline Leg adiposity & 0.3166 & 0.0140 & 0.5724 & 0.0679 & 0.0973 & 0.1628 \\
\hline Percent leg fat & 0.1570 & 0.1457 & 0.4113 & 0.0768 & 0.1056 & 0.1089 \\
\hline Trunk adiposity & 0.8720 & 0.0307 & 0.2960 & 0.1580 & 0.0723 & 0.2510 \\
\hline Percent trunk fat & 0.6508 & 0.0701 & 0.2799 & 0.1327 & 0.0632 & 0.1889 \\
\hline Waist circumference & 0.2689 & 0.0006 & 0.1837 & 0.0006 & 0.1149 & 0.0008 \\
\hline
\end{tabular}

$* p$ value $<0.05$

${ }^{a}$ All models adjusted for the following covariates: tanner stage, sex, age, ethnic group, total daily energy intake, genetic admixture, and socioeconomic status

Table 5 Total daily energy intake (kcal/day) and total daily lactose intake (g/day) according to LP status

\begin{tabular}{llllll}
\hline Population & Variable & LCT allele & Mean & SD & $p$ value \\
\hline Total & Total daily energy intake & LP & $1,924.4$ & 462.7 & 0.1401 \\
& & Non-LP & $1,843.9$ & 460.0 & \\
& Total daily lactose intake & LP & 19.315 & 11.411 & 0.0006 \\
& & Non-LP & 15.966 & 9.785 & \\
Female & Total daily energy intake & LP & $1,842.9$ & 406.7 & 0.2213 \\
& & Non-LP & $1,753.1$ & 44.20 & \\
& Total daily lactose intake & LP & 18.147 & 11.664 & 0.0576 \\
& & Non-LP & 14.655 & 9.147 & \\
Male & Total daily energy intake & LP & $2,002.7$ & 501.0 & 0.2757 \\
& & Non-LP & $1,917.3$ & 463.9 & \\
& Total daily lactose intake & LP & 20.437 & 11.126 & 0.0032 \\
& & Non-LP & 15.220 & 10.330 & \\
\hline
\end{tabular}

FMI was significantly associated $(p=0.012)$ with the LP allele but was not associated with the other tissue compartments, while in females, there were no significant associations with any of the tissue compartments (Table 3).

The significant association between FMI and the LP allele in the entire population and in males led to the dissection of FMI into body compartments with the intention of understanding the distribution of adipose tissue associated with the LP allele. In the entire sample, a significant association was found between the LP allele and leg adiposity $(p=0.032)$, as well as leg adipose percentage $(p=0.018)$. Moreover, the association with trunk adiposity trended toward significance $(p=0.094)$, while a significant association was found for trunk adipose percentage $(p=0.044)$ (Table 2). Among EAs and AAs, we found no association between the LP allele and any adipose compartments; however, among HAs, the LP allele trended toward a significant association with leg adiposity $(p=0.097)$, trunk fat $(p=0.072)$, and trunk adipose percentage $(p=0.063)$ (Table 4). Among males, a positive significant association was observed between the LP allele and leg adiposity $(p=0.033)$, leg adipose percentage $(p=0.026)$, trunk adiposity $(p=0.046)$, and trunk adipose percentage $(p=0.017)$. In contrast, no associations were found among females between any of the adipose-related body compartments and the LP allele (Table 3).

In the entire sample, a significant positive association was found between the LP allele and waist circumference $(p=0.008)$ (Table 2). None of the ethnic groups individually displayed a significant association with waist circumference; however, waist circumference in males was positively associated $(p=0.045)$ with the LP allele, while in females it was not $(p=0.269)$ (Table 3$)$. 
Association of LP allele with lactose consumption

Analysis of dietary lactose intake was also conducted in the entire population. Positive correlations existed between the LP allele and percentage of total calories from lactose $(p=0.010)$, and between percentage of total calories from lactose and FMI $(p=0.0005)$. The association between total daily lactose intake and BMI trended toward significance ( $p=0.083$ ), whereas no correlation existed between total daily lactose intake and BMCi $(p=0.756)$. In multiple linear regression analyses of the same variables, a significant positive association was observed between the LP allele and percentage of total calories from lactose $(p=0.017)$. Further evaluation included an interaction term between the LP allele and percentage of total calories from lactose, which was also significant $(p=0.025)$. The association between percentage of total calories from lactose and FMI trended toward significance $(p=0.056)$. No significant association was found between percent lactose intake and BMI $(p=0.289)$ or between lactose intake and $\mathrm{BMCi}(p=0.280)$.

$T$-tests were conducted in the entire population and by gender in order to compare lactose intake between LP and nonLP groups and to compare total daily energy intake between the two groups (Table 5). In the overall population, LP individuals consumed significantly more lactose $(p=0.001)$ but not more overall calories (0.1401) than non-LP individuals. LP males consumed significantly more lactose $(p=0.003)$ but not more overall calories than non-LP males $(p=0.276)$. LP females nearly consumed significantly more grams of lactose ( $p=0.058$ ) but did not consume more calories than their nonLP counterparts $(p=0.221)$.

\section{Discussion}

The etiology of obesity in the US is complex (McAllister et al. 2009). Given the alarming rate of childhood obesity and related cardiometabolic complications (Ogden et al. 2006), the consideration of less traditional factors influencing obesity is paramount. This study provides insight into the relationships between lactase persistence (assessed via the LCT SNP), lactose intake, and their potential effects on variation in levels of total body fat, lean, and bone mass. We further qualified fat distribution by evaluating specific depots, particularly in the trunk and leg regions. In the overall sample, our data suggest that children carrying the LP allele are more likely to have a higher BMI than those without the allele, especially in boys, and that the distribution of added weight corresponded to adipose tissue in the legs and waist.

The gender differences observed in our results are of interest. It was found that male LP allele carriers exhibited significantly increased BMI, FMI, leg adiposity, trunk adiposity, and waist circumference, whereas none of these associations were significant in females. Other groups have similarly confirmed a significantly lower dairy consumption in females when compared to males in adolescent cohorts (Larson et al. 2006). When considering that girls consumed less lactose than boys, it could be possible that the association between LP allele and adiposity measures responds to a potential threshold effect of lactose consumption that was not achieved for girls in our sample. This explanation, although potentially feasible, will require further scientific investigation that goes above and beyond the scope of this study.

Our results suggest that LP allele carriers in our overall sample have higher BMIs and greater FMI than their nonLP counterparts. LP allele carriers' ability to produce lactase provides the gastrointestinal tract with the enzyme that permits the utilization of calories in lactose and associated ingested foods. Since overall caloric intake between the LP and non-LP groups did not differ, it is possible that the significant observed differences in BMI between the two LP allele groups may have more to do with non-LP carriers' inability to digest lactose than the LP carriers' ability to take advantage of the calories in lactose. Non-LP carriers retain ingested and undigested lactose within the gut, causing an osmolality imbalance, potentially leading to the malabsorption of not only lactose, but also of any associated ingested nutrients (Swallow et al. 2001; ObermayerPietsch et al. 2007). Therefore, lactose and concurrently ingested nutrients may pass through the gut without being effectively absorbed, resulting in decreased caloric utilization of ingested foods and a lower average BMI.

Similar findings have been previously reported that support our data. For example, Lehtimäki and colleagues (Lehtimäki et al. 2006) reported that LP individuals consumed significantly more dairy than their non-LP counterparts; however, their findings cannot necessarily be transferred into lactose consumption. Through our vast experience evaluating dietary data from recalls, we understand that one serving of dairy is not necessarily equivalent to a particular amount of lactose, calories, or quantity to another form of dairy serving. Given that dairy products form a foundational part of the USDA nutritional guidelines, and multiple servings per day are recommended to the general public (USDA 2012), our results bring to the forefront the need to consider individual's genetic makeup when developing individual therapies to overcome excessive body fat accumulation.

Recent concerns have arisen for non-LP individuals with the emergence of "hidden" lactose that is added to foods and drinks without appearing on the label. Because lactose has nearly one-sixth the sweetness of sucrose (common table sugar) and lactose is not easily metabolized by yeast, 
it can be added to foods and drinks without producing carbon dioxide or an unpleasant taste. In the United States, production of lactose increased more than fivefold between 1979 and 1999 alone (Matthews et al. 2005). Lactose is used in food as a browning agent in bread and cake mixes and is added to processed meats, chicken, and several types of drinks (Matthews et al. 2005; NIDDK). The lactose introduced into many of these common non-dairy foods may lead to unnoticed malabsorption of nutrients in nonLP individuals and contribute to the lower observed BMI in non-LP allele carriers.

One of the primary strengths of this study was the use of dietary lactose, rather than merely dairy intake, in our analyses. This aspect is of great importance and potentially provides a more direct link to understanding the role of the LCT gene and lactase production on BMI. While several other studies (Almon et al. 2010; Corella et al. 2011) have used dairy intake to elucidate the effects of the LCT gene on BMI, we consider counting servings of dairy to be potentially misrepresentative since dairy products can have a variety of calories, quantity, and lactose content, as previously mentioned. Other strengths of our study include an ethnically diverse sample, the inclusion of admixture estimates to control for population stratification, and very detailed body composition and anthropometric measurements.

Study limitations include the use of the 24-h dietary recall that may not give an ideal long-term picture of food intake (Johnson 2002). Additionally, the reliability of a small sample size and cross-sectional analysis should be kept in mind when interpreting the results of this study. Moreover, the results for this study were derived from one geographical location and may not apply equally in other contexts. Regardless of our attempts to control for potential cultural biases associated with the main variables of the study, we recognize that cultural variability cannot just be modeled by ethnic classification and socioeconomic status alone, and that our data are limited by lack of other cultural factors that could impact the relationships among LP genetic variation, lactose intake, and fat accumulation. Finally, we have only tested one of several LP alleles. Other LP alleles have arisen independently in other groups (Imtiaz et al. 2007; Ingram et al. 2007, 2009; Tishkoff et al. 2007; Büning et al. 2004; Itan et al. 2010). It is possible that not all individuals who lack the particular LP allele tested are in fact lactose intolerant. However, given the likely ancestral background of the participants in this study, and the origin of the other LP alleles (East Africa and Middle East), this limitation may not constitute a major concern.

The LP allele of the LCT SNP may contribute to the complexity of today's novel and obesogenic environment. This SNP is primarily studied in adults and extensive research has been lacking in children. Future studies will need to confirm and refine the findings of our research and examine in greater detail the potential physiological mechanisms by which this allele may interact with dietary intake to affect body composition and health outcomes.

Acknowledgments The authors would like to thank the study participants and their families, and the following National Institutes of Health (NIH) grants: R01-DK067426, T32-H1007457, R01 DA025095, 5P30DK056336, CA47888, and P60-DK079626. The opinions expressed are those of the authors and not necessarily those of the NIH or any other organization with which the authors are affiliated.

Conflict of interest The authors declare no conflict of interest.

\section{References}

Almon R, Patterson E, Nilsson T, Engfeldt P, Sjöström M (2010) Body fat and dairy product intake in lactase persistent and nonpersistent children and adolescents. Food Nutr Res 54. doi: 10.3402/fnr.v54i0.5141

Almon R, Álvarez-León E, Serra-Majem L (2012) Association of the European lactase persistence variant (LCT-13910 C > T polymorphism) with obesity in the Canary Islands. PloS one 7(8). doi:10.1371/journal.pone.0043978

Berkey C, Rockett H, Willett W, Colditz G (2005) Milk, dairy fat, dietary calcium, and weight gain: a longitudinal study of adolescents. Arch Pediatr Adolesc Med 159(6):543-550. doi: 10.1001/archpedi.159.6.543

Bersaglieri T, Sabeti P, Patterson N, Vanderploeg T, Schaffner S, Drake J, Rhodes M, Reich D, Hirschhorn J (2004) Genetic signatures of strong recent positive selection at the lactase gene. Am J Hum Genet 74(6):1111-1120. doi:10.1086/421051

Bouchard C (1991) Current understanding of the etiology of obesity: genetic and nongenetic factors. The American journal of clinical nutrition 53 (6 Suppl)

Büller H, Kothe M, Goldman D, Grubman S, Sasak W, Matsudaira P, Montgomery R, Grand R (1990) Coordinate expression of lactase-phlorizin hydrolase mRNA and enzyme levels in rat intestine during development. J Biol Chem 265(12):6978-6983

Büning C, Schmidt H, Lochs H, Ockenga J (2004) Genetic components of lactose intolerance and community frequency. J Bone Miner Res 19(10). doi:10.1359/jbmr.040803

Buzinaro E, Almeida R, Mazeto G (2006) Bioavailability of dietary calcium. Arquivos Brasileiros de Endocrinologia e Metabologia 50(5):852-861

Casazza K, Dulin-Keita A, Gower B, Fernández J (2009) Relationships between reported macronutrient intake and insulin dynamics in a multi-ethnic cohort of early pubertal children. Int $\mathbf{J}$ Pediatr Obes 4(4):249-256. doi:10.3109/17477160902763366

Cirino P, Chin C, Sevcik R, Wolf M, Lovett M, Morris R (2002) Measuring socioeconomic status: reliability and preliminary validity for different approaches. Assessment 9(2):145-155. doi: 10.1177/10791102009002005

Corella D, Arregui M, Coltell O, Portolés O, Guillem-Sáiz P, Carrasco P, Sorlí J, Ortega-Azorín C, González J, Ordovás J (2011) Association of the LCT-13910C $>\mathrm{T}$ polymorphism with obesity and its modulation by dairy products in a Mediterranean population. Obesity 19(8):1707-1714. doi:10.1038/oby.2010.320

Debongnie J, Newcomer A, McGill D, Phillips S (1979) Absorption of nutrients in lactase deficiency. Dig Dis Sci 24(3):225-231. doi:10.1007/bf01308435 
Enattah N, Sahi T, Savilahti E, Terwilliger J, Peltonen L, Järvelä I (2002) Identification of a variant associated with adult-type hypolactasia. Nat Genet 30(2):233-237. doi:10.1038/ng826

Hanks L, Casazza K, Willig A, Cardel M, Beasley T, Fernandez J (2010) Associations among calcium intake, resting energy expenditure, and body fat in a multiethnic sample of children. J Pediatr 157(3):473-478. doi:10.1016/j.jpeds.2010.02.065

I.O.M. (2010) Dietary reference intakes for calcium and vitamin D. National Academy Press, Committee to Review Dietary Reference Intakes for Vitamin D and Calcium: Food and Nutrition Board, Institute of Medicine

Imtiaz F, Savilahti E, Sarnesto A, Trabzuni D, Al-Kahtani K, Kagevi I, Rashed M, Meyer B, Järvelä I (2007) The T/G 13915 variant upstream of the lactase gene (LCT) is the founder allele of lactase persistence in an urban Saudi population. J med genet 44(10). doi:10.1136/jmg.2007.051631

Ingram $\mathrm{C}$, Elamin $\mathrm{M}$, Mulcare $\mathrm{C}$, Weale $\mathrm{M}$, Tarekegn $\mathrm{A}$, Raga $\mathrm{T}$, Bekele E, Elamin F, Thomas M, Bradman N, Swallow D (2007) A novel polymorphism associated with lactose tolerance in Africa: multiple causes for lactase persistence? Hum Genet 120(6):779-788. doi:10.1007/s00439-006-0291-1

Ingram C, Raga T, Tarekegn A, Browning S, Elamin M, Bekele E, Thomas M, Weale M, Bradman N, Swallow D (2009) Multiple rare variants as a cause of a common phenotype: several different lactase persistence associated alleles in a single ethnic group. J Mol Evol 69(6):579-588. doi:10.1007/s00239-009-9301-y

Itan Y, Jones B, Ingram C, Swallow D, Thomas M (2010) A worldwide correlation of lactase persistence phenotype and genotypes. BMC Evol Biol 10:36. doi:10.1186/1471-2148-10-36

Johnson R (2002) Dietary intake — how do we measure what people are really eating? Obes Res 10(Suppl):1. doi:10.1038/oby.2002.192

Kettunen J, Silander K, Saarela O, Amin N, Müller M, Timpson N, Surakka I, Ripatti S, Laitinen J, Hartikainen A-L, Pouta A, Lahermo P, Anttila V, Männistö S, Jula A, Virtamo J, Salomaa V, Lehtimäki T, Raitakari O, Gieger C, Wichmann E, Van Duijn C, Smith G, McCarthy M, Järvelin M-R, Perola M, Peltonen L (2010) European lactase persistence genotype shows evidence of association with increase in body mass index. Hum Mol Genet 19(6):1129-1136. doi:10.1093/hmg/ddp561

Klimentidis Y, Divers J, Casazza K, Beasley T, Allison D, Fernandez J (2011) Ancestry-informative markers on chromosomes 2, 8 and 15 are associated with insulin-related traits in a racially diverse sample of children. Hum Genomics 5(2):79-89

Lacey S, Naim H, Magness R, Gething M, Sambrook J (1994) Expression of lactase-phlorizin hydrolase in sheep is regulated at the RNA level. Biochem J 302(Pt 3):929-935

Larson N, Story M, Wall M, Neumark-Sztainer D (2006) Calcium and dairy intakes of adolescents are associated with their home environment, taste preferences, personal health beliefs, and meal patterns. J Am Diet Assoc 106(11):1816-1824. doi:10.1016/j.jada. 2006.08.018

Lehtimäki T, Hemminki J, Rontu R, Mikkilä V, Räsänen L, Laaksonen $M$, Hutri-Kähönen $N$, Kähönen $M$, Viikari J, Raitakari O (2006) The effects of adult-type hypolactasia on body height growth and dietary calcium intake from childhood into young adulthood: a 21-year follow-up study - the Cardiovascular Risk in Young Finns Study. Pediatrics 118(4):1553-1559. doi: 10.1542/peds.2006-0542

Marshall W, Tanner J (1968) Growth and physiological development during adolescence. Annu Rev Med 19:283-300. doi: 10.1146/annurev.me.19.020168.001435

Matthews S, Waud J, Roberts A, Campbell A (2005) Systemic lactose intolerance: a new perspective on an old problem. Postgrad Med J 81(953):167-173. doi:10.1136/pgmj.2004.025551

McAllister E, Dhurandhar N, Keith S, Aronne L, Barger J, Baskin M, Benca R, Biggio J, Boggiano M, Eisenmann J, Elobeid M,
Fontaine K, Gluckman P, Hanlon E, Katzmarzyk P, Pietrobelli A, Redden D, Ruden D, Wang C, Waterland R, Wright S, Allison D (2009) Ten putative contributors to the obesity epidemic. Crit Rev Food Sci Nutr 49(10):868-913. doi: 10.1080/10408390903372599

Murakami K, Okubo H, Sasaki S (2006) No relation between intakes of calcium and dairy products and body mass index in Japanese women aged 18 to 20 y. Nutrition 22(5):490-495. doi: 10.1016/j.nut.2005.12.003

Obermayer-Pietsch B, Gugatschka M, Reitter S, Plank W, Strele A, Walter D, Bonelli C, Goessler W, Dobnig H, Högenauer C, Renner W, Fahrleitner-Pammer A (2007) Adult-type hypolactasia and calcium availability: decreased calcium intake or impaired calcium absorption? Osteoporos Int 18(4):445-451. doi:10.1007/s00198-006-0251-6

Ogden C, Carroll M, Curtin L, McDowell M, Tabak C, Flegal K (2006) Prevalence of overweight and obesity in the United States, 1999-2004. JAMA 295(13):1549-1555. doi: 10.1001/jama.295.13.1549

Olds L, Sibley E (2003) Lactase persistence DNA variant enhances lactase promoter activity in vitro: functional role as a cis regulatory element. Hum Mol Genet 12(18):2333-2340. doi: $10.1093 / \mathrm{hmg} / \mathrm{ddg} 244$

Parra E, Marcini A, Akey J, Martinson J, Batzer M, Cooper R, Forrester T, Allison D, Deka R, Ferrell R, Shriver M (1998) Estimating African American admixture proportions by use of population-specific alleles. Am J Hum Genet 63(6):1839-1851. doi: $10.1086 / 302148$

Remesar X, Tang V, Ferrer E, Torregrosa C, Virgili J, Masanés R, Fernández-López J, Alemany M (1999) Estrone in food: a factor influencing the development of obesity? Eur J Nutr 38(5):247-253

Scrimshaw N, Murray E (1988) The acceptability of milk and milk products in populations with a high prevalence of lactose intolerance. Am J Clin Nutr 48(4 Suppl):1079-1159

Sebastio G, Villa M, Sartorio R, Guzzetta V, Poggi V, Auricchio S, Boll W, Mantei N, Semenza G (1989) Control of lactase in human adult-type hypolactasia and in weaning rabbits and rats. Am J Hum Genet 45(4):489-497

Skinner J, Bounds W, Carruth B, Ziegler P (2003) Longitudinal calcium intake is negatively related to children's body fat indexes. J Am Diet Assoc 103(12):1626-1631. doi:10.1016/j.jada.2003.09.018

Slyper A, Huang WM (2009) Milk, dairy fat, and body weight in pediatrics: time for reappraisal. ICAN: Infant, Child, \& Adolescent. Nutrition 1(3):148-159

Swallow D, Poulter M, Hollox E (2001) Intolerance to lactose and other dietary sugars. Drug Metab Dispos 29(4 Pt 2):513-516

Swinburn B, Jolley D, Kremer P, Salbe A, Ravussin E (2006) Estimating the effects of energy imbalance on changes in body weight in children. Am J Clin Nutr 83(4):859-863

Tishkoff S, Reed F, Ranciaro A, Voight B, Babbitt C, Silverman J, Powell K, Mortensen H, Hirbo J, Osman M, Ibrahim M, Omar S, Lema G, Nyambo T, Ghori J, Bumpstead S, Pritchard J, Wray G, Deloukas P (2007) Convergent adaptation of human lactase persistence in Africa and Europe. Nat Genet 39(1):31-40. doi: $10.1038 / \mathrm{ng} 1946$

U.S.C.B. (2000). http://www.census.gov

USDA (2012) How much food from the dairy group is needed daily? http://www.choosemyplate.gov/food-groups/dairy-amount.html

Wang Y, Harvey C, Pratt W, Sams V, Sarner M, Rossi M, Auricchio S, Swallow D (1995) The lactase persistence/non-persistence polymorphism is controlled by a cis-acting element. Hum Mol Genet 4(4):657-662. doi:10.1093/hmg/4.4.657

Wang Y, Harvey C, Hollox E, Phillips A, Poulter M, Clay P, WalkerSmith J, Swallow D (1998) The genetically programmed downregulation of lactase in children. Gastroenterology 114(6):1230 1236. doi:10.1016/s0016-5085(98)70429-9 